\title{
Rupture process of the 2018 Hokkaido Eastern lburi earthquake derived from strong motion and geodetic data
}

Hiroaki Kobayashi ${ }^{1,2^{*} \mathbb{D}}$, Kazuki Koketsu ${ }^{1}$ and Hiroe Miyake

\begin{abstract}
The source rupture process of the 2018 Hokkaido Eastern Iburi earthquake was investigated by performing a joint inversion analysis using the strong motion and geodetic data. A fault model that consists of two fault planes was constructed by considering the relocated aftershock distribution and the focal mechanisms. The inversion result showed that the large slip occurred at approximately $22 \mathrm{~km}$ depth, which was much shallower than the hypocentral depth. Our results showed that the rupture initiated on the minor fault plane around the hypocenter and the major fault plane started to rupture 4-6s after the rupture initiation. Although the shape of the minor fault plane has not been clearly determined, the major fault plane appears to be high-angle, east-dipping. An additional inversion with only the major fault plane showed that the strong ground motion near the source was mainly generated from the major fault plane. The total seismic moment estimated by the inversion with the two fault-plane model was $1.1 \times 10^{19} \mathrm{Nm}$, which yielded an $M_{w}$ of 6.6. Using the inversion result of the two fault-plane model, we simulated the ground surface and borehole waveforms at strong motion station IBUH03 where the large velocity pulse was observed on the ground surface. The simulations suggest that this large velocity pulse was generated from the combination of the large slip of the source and large site amplification of the velocity structure between the ground surface and borehole seismometers.
\end{abstract}

Keywords: Rupture process, 2018 Hokkaido Eastern Iburi earthquake, Strong motion, Geodetic data

\section{Introduction}

On September 5, 2018, at 18:08 (UTC), an $M_{\mathrm{JMA}}$ (Japan Meteorological Agency (JMA) magnitude) 6.7 earthquake occurred in the eastern Iburi region in Hokkaido (Fig. 1). Strong ground motion generated by the earthquake and the induced landslides caused severe damage to the region. According to the Fire and Disaster Management Agency (2019), the earthquake caused 42 fatalities and 462 houses were completely destroyed. The hypocentral depth of the earthquake as determined by the JMA was $37 \mathrm{~km}$, indicating that the earthquake was an inland earthquake. The source region is located in the west of the Hidaka Mountains (Fig. 1), which were formed due

\footnotetext{
*Correspondence: kohiroak@kobori-takken.co.jp; khiro@eri.u-tokyo.ac.jp ${ }^{1}$ Earthquake Research Institute, University of Tokyo, 1-1-1 Yayoi, Bunkyo-ku, Tokyo, Japan

Full list of author information is available at the end of the article
}

to collision between the Kuril arc and the northeast Japan arc. Because of this tectonic setting, seismic refraction/ wide-angle reflection experiments across the Hidaka Mountains, which also cross the source region of the earthquake, were conducted to investigate the crustal evolution of the arc-arc collision zone (Iwasaki et al. 2004). The experiments revealed a thick and complex crustal structure in the source region of the earthquake. The complex structure has also been indicated by seismic tomography (Kita et al. 2012, 2014). The focal mechanism determined by the Global Centroid-Moment-Tensor (CMT) project (Ekström et al. 2012) showed this earthquake to be a reverse fault with an ENE-WSW pressure axis (Fig. 1) and it corresponds to the tectonic stress field in the region.

One of the notable features of this earthquake is that the maximum seismic intensity of 7 , which is the largest value in the JMA seismic intensity scale, was observed 


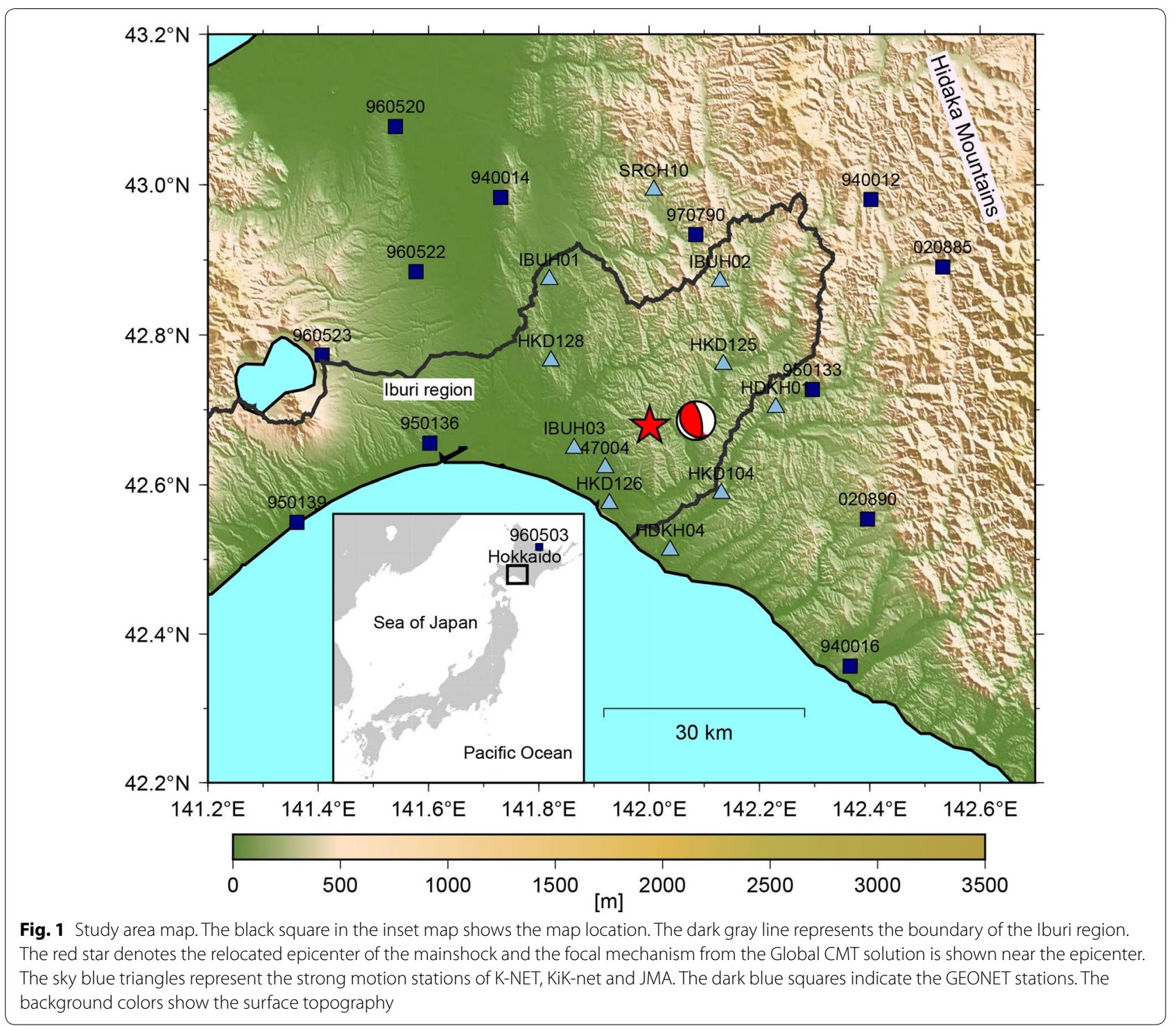

at strong motion stations 47004 and IBUH01 near the source region despite the hypocentral depth of $37 \mathrm{~km}$ (Fig. 1). Moreover, velocity pulses with maximum amplitudes larger than $100 \mathrm{~cm} / \mathrm{s}$ were observed in the ground surface records at stations such as 47004, HKD126, and IBUH03. To investigate the causes of these strong ground motions, it is necessary to investigate the rupture process of the earthquake in order to understand the physics of the source. Therefore, we performed a joint source inversion using strong motion and geodetic data. We used not only strong motion data but also geodetic data because the geodetic Green's function is less sensitive to the velocity structure model than the strong motion Green's function (Wald and Graves 2001), which makes the geodetic data useful for constructing a source model.

\section{Data and methods}

We selected 11 strong motion stations from K-NET, KiKnet, and JMA stations considering hypocentral distance and azimuthal distribution (Fig. 1). We used borehole records for the KiK-net stations. For the inversion analysis, we used velocity waveforms obtained by integrating the acceleration waveforms. We also applied a band-pass filter between 0.05 and $0.4 \mathrm{~Hz}$ to the velocity waveforms and resampled them with $0.25 \mathrm{~s}$ intervals. We excluded a UD component at station IBUH03 whose sensor was broken and a UD component at station 47004 that seemed to contain a large amount of noise; thus, we used 31 components of 11 strong motion stations. For the geodetic data, we used the daily coordinate of the F3 solution of the Geospatial Information Authority of Japan (GSI) 
(Nakagawa et al. 2009). We used the horizontal components of 12 Global Navigation Satellite System Earth Observation Network System (GEONET) stations whose epicentral distances were less than $60 \mathrm{~km}$ (Fig. 1), except for two stations whose tilts were reported after the earthquake (GSI 2018). We set station 960503 as a reference station (Fig. 1) and calculated the coseismic displacement by comparing 5 days averages between 2 and 6 days prior to and after the earthquake.

We used the inversion method developed by Yoshida et al. (1996) and Hikima and Koketsu (2005). The method is based on the multi-time-window linear inversion method and the linear problem is solved using the nonnegative least squares method under the spatiotemporal smoothness constraint. The weight of the spatiotemporal smoothness constraint is determined by minimizing the Akaike's Bayesian information criterion (Akaike 1980). We calculated strong motion Green's functions using the method of Kohketsu (1985). For each of the strong motion stations, we constructed an averaged one-dimensional (1D) velocity structure model between the source and the station from the Japan Integrated Velocity Structure Model (JIVSM) (Koketsu et al. 2008, 2012). We calculated the geodetic Green's functions using the method of Zhu and Rivera (2002). We constructed an averaged 1D velocity structure model of the area shown in Fig. 1 from the JIVSM and used it for all GEONET stations.

\section{Fault model}

To construct a fault model, we first relocated the hypocenters of the mainshock and aftershocks using the double-difference earthquake location method (Waldhauser and Ellsworth 2000). We used $P$ - and $S$-wave arrival times picked by JMA that were labeled as "high" reliability and used the 1D velocity structure model of JMA2001 (Ueno et al. 2002). Although we relocated 1 month aftershocks, we used 24-h aftershocks to see the region directly affected by the mainshock. Figure 2a shows the map view of the relocated epicenters of the mainshock and the 24-h aftershocks. As shown in the figure, the aftershock distribution is highly complex. On the whole, the aftershocks are distributed in the NNE-SSW direction. However, looking into the details, the aftershocks of the region between the purple lines in Fig. 2a are distributed in the NNW-SSE direction. According to the Global CMT solution, the strike direction of the mainshock is NNW-SSE (Fig. 1) and the F-net moment tensor solution and the JMA CMT solution also support this strike direction. Figure $2 \mathrm{~b}$ shows the cross section of the region between the purple lines. It suggests that the fault exhibits a high-angle dip to the east. The hypocenter of the mainshock was relocated at $41 \mathrm{~km}$ depth (Fig. 2c). The uncertainty $(2 \sigma)$ of this depth was estimated to be $0.9 \mathrm{~km}$ by a "delete-half" jackknife test (Tichelaar and Ruff, 1989). We randomly deleted a half of differential travel time data and performed the hypocenter relocation. This procedure was repeated 100 times.

Figure 2d, e show the Global CMT solution and the JMA first motion solution of the mainshock. The Global CMT solution indicates a major fault plane where the majority of the seismic moment release occurred during the earthquake, while the first motion solution, which is determined using the polarity of the $P$-wave first motion, indicates a fault plane where the rupture was initiated. As shown in Fig. 2d, e, these two mechanisms are different from each other, indicating that a minor fault plane, where the rupture was initiated, is necessary.

Considering the above result, we assumed two fault planes for the inversion analysis. One is an east-dipping major fault plane whose length, width, and strike and dip angles are $21 \mathrm{~km}, 24 \mathrm{~km}, 350^{\circ}$, and $70^{\circ}$, respectively. Another is a west-dipping minor fault plane whose length, width, and strike and dip angles are $21 \mathrm{~km}, 6 \mathrm{~km}$, $170^{\circ}$, and $65^{\circ}$, respectively. The fault sizes were determined considering the aftershock area. The locations of the fault planes are described in Fig. 2a-c. Because the fault planes of the north and south parts of the purple lines of Fig. 2a were not clear from the aftershock distribution, we did not bend the faults along the strike direction.

For the inversion analysis, we divided these two fault planes into subfaults having lengths and widths of $3 \mathrm{~km}$ and $3 \mathrm{~km}$, respectively. Thus, the total number of subfaults is 70 . The basis source time function for each subfault is represented by a five-boxcar, nonoverlapped functions. The rise time of each boxcar function is $1 \mathrm{~s}$. We assumed a circular rupture front from the rupture initiation points. We assumed that the rupture initiation point of the minor fault plane is the hypocenter of the earthquake and that of the major fault plane is the bottom center subfault. We calculated the rupture start timing of the major fault plane by the distance from the hypocenter and the rupture front velocity $\left(V_{r}\right)$, which gave us the timing of the first time windows of each subfault.

\section{Results}

Figure 3a shows the resultant slip distribution of the inversion analysis for the two fault-plane model. We determined $V_{r}$ to be $2.8 \mathrm{~km} / \mathrm{s}$ considering the variance of the waveforms (Additional file 1: Figure S1). On the major fault plane, a maximum slip of $2.9 \mathrm{~m}$ was obtained at a depth of around $22 \mathrm{~km}$, which is approximately $19 \mathrm{~km}$ shallower than the hypocenter. This large slip region was again located at a similar depth even when $V_{r}$ is faster than $2.8 \mathrm{~km} / \mathrm{s}$ (Additional file 1: Figure S2). On the minor fault plane, approximately $1 \mathrm{~m}$ slip was obtained around 


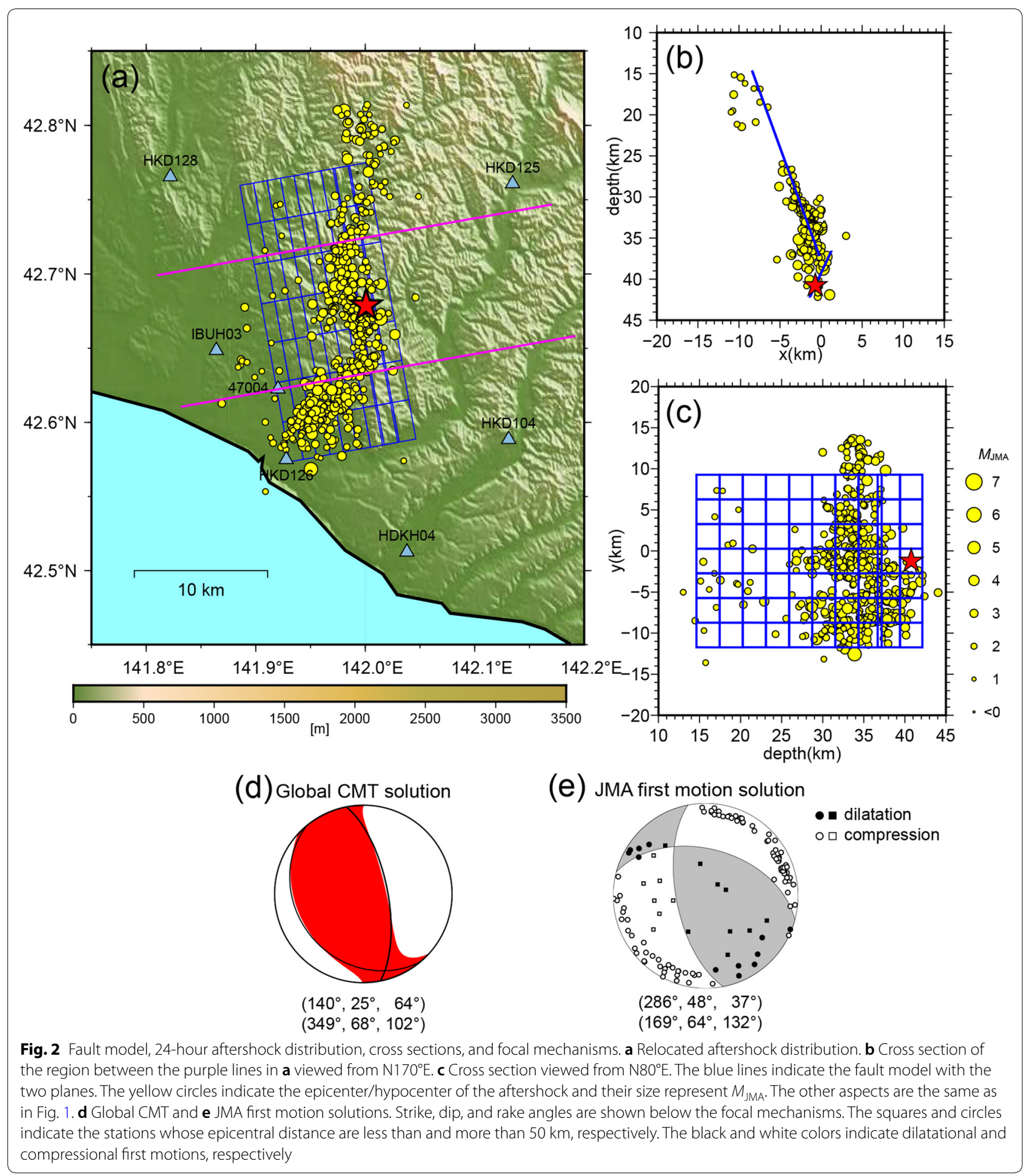

the hypocenter. The snapshots of the slip distribution for each $2 \mathrm{~s}$ interval (Fig. 3b) show the small rupture on the minor fault plane at $0-4 \mathrm{~s}$. Moreover, a rupture started on the major fault plane 4-6 s after the rupture initiation. The rupture propagated in the up-dip direction and the large rupture occurred at 6-10 s on the major fault plane. The moment rate function has a peak around $8 \mathrm{~s}$ that corresponds to the large rupture (Fig. 3c). The estimated total seismic moment of the earthquake is $1.1 \times 10^{19} \mathrm{Nm}$, which yields an $M_{w}$ of 6.6. Figure 3d shows the observed 

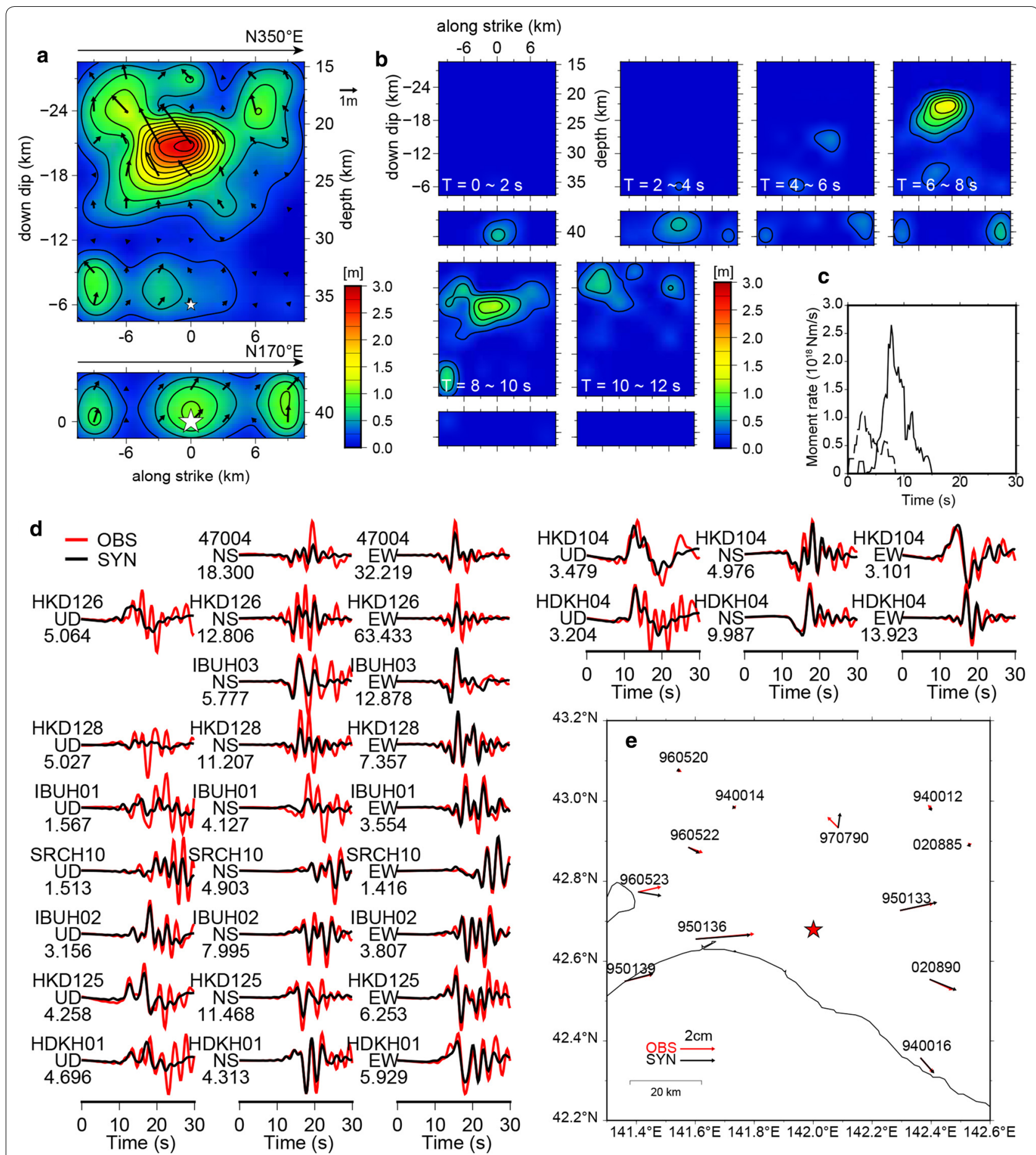

Fig. 3 Inversion results for the two fault-plane model. a Slip distribution. The large and small white stars denote the hypocenter of the mainshock and the assumed rupture initiation point of the major fault plane, respectively. $\mathbf{b}$ Two-second snapshots of the slip. The contour intervals are $0.25 \mathrm{~m}$ in panels $\mathbf{a}$ and $\mathbf{b}$. c Moment rate functions of each fault plane. The solid and dashed lines represent the moment rate functions of the major and minor faults, respectively. $\mathbf{d}$ Observed (red) and synthetic (black) strong motion waveforms. Station names, components, and the maximum amplitude of the observed waveforms (cm/s) are shown to the left of each waveform. e Observed (red arrows) and synthetic (black arrows) static displacements of the horizontal components. The red star denotes the epicenter of the mainshock. Station names are indicated near the arrows 
and synthetic strong motion waveforms. Our model well reproduced the velocity pulses of the EW components at stations 47004 and IBUH03 (Fig. 3d). However, the amplitude of the EW components of the synthetic waveform of station HKD126 is only half of the observed one. We will discuss these velocity pulses in "Discussion and conclusions" section. The geodetic data fittings are generally good, except for station 970790 where the directions are different between the observed and synthetic displacements (Fig. 3e). One possible reason for the discrepancy is that station 970790 may have been affected by local deformation.

\section{Discussion and conclusions}

According to the crustal structure model obtained by the seismic refraction/wide-angle reflection experiments (Fig. 10 in Iwasaki et al. 2004), the boundary between the lower and upper crust lies at approximately $25 \mathrm{~km}$ depth in the source region. This indicates that the large slip occurred in the brittle upper crust. The hypocenter was relocated at $41 \mathrm{~km}$ depth and is located at the lowermost region of the aftershock distribution. This suggests that the brittle part may have extended to that depth in the source region. Note that the Moho depth in the source region has been estimated to be $32-34 \mathrm{~km}$ (Katsumata 2010, Matsubara et al. 2017). The centroid depth of the Global CMT solution is $31 \mathrm{~km}$, which is approximately $9 \mathrm{~km}$ deeper than the depth of the large slip in our model. Hjörleifsdóttir and Ekström (2010) showed that centroid depth of the Global CMT solution can be biased when near-source crustal structure is different from the PREM model (Dziewonski and Anderson 1981). The thick crust in the near-source region, which is not considered in the Global CMT calculation, may affect its centroid depth estimation.

We constructed a fault model that consists of two fault planes. We obtained approximately $1 \mathrm{~m}$ slip on the minor fault plane. However, the rake angle of the slip differs from the JMA first motion solution (Fig. 2e). This suggested that the strike and dip angles of this minor fault plane should be modified, or that the first motion solution was not appropriately obtained. The takeoff angles for the JMA first motion solution were calculated using the 1D velocity structure model of JMA2001 (Ueno et al. 2002). In Fig. 2e, we plotted the polarity distribution which was calculated using the JMA2001 model and the relocated hypocenter. This shows that the fault-plane solutions are determined by the polarity of near-source stations. Because the takeoff angles depend on the velocity structure model, the takeoff angles, especially of the near-source stations, may be changed if we consider the complex crustal structure near the source. However, we did not conduct further investigation into the minor fault plane around the hypocenter, instead we did an additional joint source inversion which suggested that the minor fault plane around the hypocenter contributed litthe to the velocity pulses at the near-source stations. In this additional source inversion, we only considered the major fault plane and extended it to the down-dip direction (Fig. 4a). We also changed the rupture initiation point from the hypocenter to the bottom center subfault and redetermined $V_{r}$ to be $2.9 \mathrm{~km} / \mathrm{s}$ (Fig. $4 \mathrm{~b}$ ). The other parameters were kept the same as in the two fault-plane model. The results showed that the fitting of the velocity pulses was little changed from that of the two faultplane model (Fig. 4c), although the overall fitting is a little worse than that of the two fault-plane model.

The large velocity pulses were observed at the ground surface at stations 47004, HKD126, and IBUH03. Because we used the borehole records at station IBUH03, we calculated the waveforms at the ground surface using the two fault-plane model. Figure 5 shows the comparisons of observed and synthetic waveforms of both ground surface and borehole at station IBUH03. Because we could not reproduce the ground surface waveform satisfactorily, we also calculated the ground surface waveform using the 1D velocity structure model, which was constructed by combining the near surface KiK-net PS logging data with the JIVSM model. Densities were calculated using an empirical equation between $V_{p}$ and density for $V_{p} \geq 1.5 \mathrm{~km} / \mathrm{s}$ (Ludwig et al. 1970). For $V_{p}<1.5 \mathrm{~km} / \mathrm{s}$, we determined density by referring to the subsurface data from station HKD126. $Q_{p}$ and $Q_{s}$ were calculated using the equations $Q_{s}=1000 \times \mathrm{V}_{s} / 5$ and $Q_{p}=1.7 \times Q_{s}$, which are the same as those used in the JIVSM model. Although the maximum amplitude of the synthetic waveform of the combined model is larger than that of the JIVSM model, it was still much smaller than the maximum amplitude of the observed waveform (Fig. 5). This suggests that the ground surface waveform at station IBUH03 is highly affected by a local site effect that cannot be explained by the 1D model. It also suggested that the underestimation of maximum amplitude of the synthetic waveforms at station HKD126 in our inversion analysis could be attributed to a similar reason.

We performed the joint source inversion analysis of the 2018 Hokkaido Eastern Iburi earthquake using the strong motion and geodetic data. We constructed a fault model that consisted of two fault planes by considering the aftershock distribution and the focal mechanisms. The inversion result showed that the earthquake was initiated with a small rupture on the minor fault plane and then the main rupture occurred on the major fault plane. The total duration of the rupture was approximately $15 \mathrm{~s}$. Although the relocated hypocenter of the earthquake is at $41 \mathrm{~km}$ depth, the large slips were estimated to have occurred 

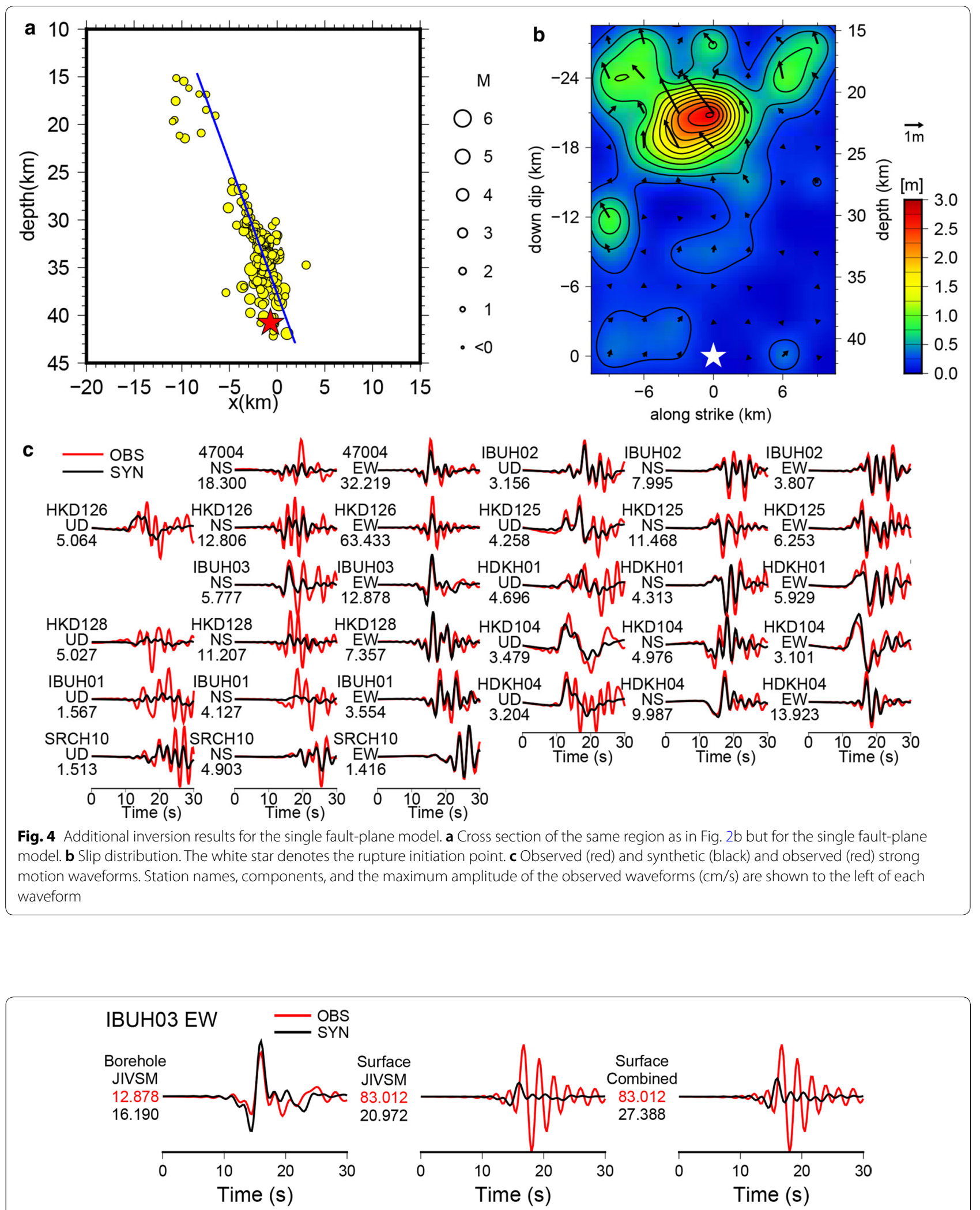

Fig. 5 Observed and synthetic borehole and ground surface waveforms of EW components at station IBUH03. Locations, velocity structure models for calculating synthetic waveforms, and maximum amplitudes of the observed (red) and synthetic (black) waveforms are shown to the left of each waveform 
at around $22 \mathrm{~km}$ depth. This shallow large slip probably contributed to the observed strong ground motion of the earthquake. Our examination of the ground surface and borehole records from station IBUH03 suggests that the velocity pulses were generated from the large slip of the source and were highly amplified by the local site effect.

\section{Additional file}

Additional file 1: Figure S1. Rupture front velocity versus waveform variance for the two fault-plane model. Figure S2. Slip distribution for various rupture front velocities $\left(V_{r}\right)$

\section{Abbreviations}

JMA: Japan Meteorological Agency; CMT: Centroid-Moment-Tensor; GSI: Geospatial Information Authority of Japan; GEONET: Global Navigation Satellite System Earth Observation Network System; JIVSM: Japan Integrated Velocity Structure Model; 1D: One-dimensional; NIED: National Research Institute for Earth Science and Disaster Resilience.

\section{Acknowledgements}

We would like to thank NIED for providing the strong motion data and JMA for providing the strong motion data and their catalog data. We also would like to thank GSI for providing the GEONET F3 solutions. We used the Generic Mapping Tools (Wessel et al. 2013) for drawing the figures. We thank Dr. Luca Moratto and an anonymous reviewer for helpful comments.

\section{Authors' contributions}

HK conducted the analysis. All authors drafted the manuscript. All authors read and approved the final manuscript.

\section{Funding}

This study was supported by the Grant-in-Aid for Special Purposes of MEXT (No. 18K19952).

\section{Availability of data and materials}

The K-NET and KiK-net strong motion data are available at the Web site of strong-motion seismograph networks operated by the National Research Institute for Earth Science and Disaster Resilience (NIED) (http://www.kyosh in.bosai.go.jp/). The JMA strong motion data are available at their Web site (https://www.data.jma.go.jp/svd/eqev/data/kyoshin/jishin/1809060307 _hokkaido-iburi-tobu/index.html, in Japanese). The JMA catalog data are available at the Hi-net web site operated by the NIED (http://www.hinet.bosai .go.jp/?LANG=en). The GEONET F3 solutions are available at the GSI Web site (http://datahouse1.gsi.go.jp/terras/terras_english.html).

\section{Competing interests}

The authors declare that they have no competing interests.

\section{Author details}

${ }^{1}$ Earthquake Research Institute, University of Tokyo, 1-1-1 Yayoi, Bunkyo-ku, Tokyo, Japan. ${ }^{2}$ Present Address: Kobori Research Complex Inc., 6-5-30 Akasaka, Minato-ku, Tokyo, Japan.

Received: 28 February 2019 Accepted: 22 May 2019

Published online: 31 May 2019

\section{References}

Akaike H (1980) Likelihood and the Bayes procedure. Trabajos de Estadistica y de Investigacion Operativa 31:143-166. https://doi.org/10.1007/BF028 88350
Dziewonski AM, Anderson DL (1981) Preliminary reference Earth model. Phys Earth Planet Int 25:197-356. https://doi.org/10.1016/0031-9201(81)90046

Ekström G, Nettles M, Dziewonski AM (2012) The global CMT project 2004 2010: centroid-moment tensors for 13,017 earthquakes. Phys Earth Planet Int 200-201:1-9. https://doi.org/10.1016/j.pepi.2012.04.002

Fire and Disaster Management Agency (2019) The 34th report of the 2018 Hokkaido Eastern Iburi earthquake. http://www.fdma.go.jp/bn/2018/ detail/1074.html. Last accessed 26 February 2019 (in Japanese)

GSI (2018) The 2018 Hokkaido Eastern Iburi Earthquake: fault model (preliminary), http://www.gsi.go.jp/cais/topic180912-index.html. Last accessed 26 February 2019 (in Japanese)

Hikima K, Koketsu K (2005) Rupture processes of the 2004 Chuetsu (midNiigata prefecture) earthquake, Japan: a series of events in a complex fault system. Geophys Res Lett 32:L18303. https://doi.org/10.1029/2005G L023588

Hjörleifsdóttir V, Ekström G (2010) Effects of three-dimensional Earth structure on CMT earthquake parameters. Phys Earth Planet Int 179:178-190. https ://doi.org/10.1016/j.pepi.2009.11.003

Iwasaki T, Adachi K, Moriya T, Miyamachi H, Matsushima T, Miyashita K, Takeda T, Taira T, Yamada T, Ohtake K (2004) Upper and middle crustal deformation of an arc-arc collision across Hokkaido, Japan, inferred from seismic refraction/wide-angle reflection expriments. Tectonophysics 388:59-73. https://doi.org/10.1016/j.tecto.2004.03.025

Katsumata A (2010) Depth of the Moho discontinuity beneath the Japanese islands estimated by traveltime analysis. J Geophys Res 115:B04303. https $\because / /$ doi.org/10.1029/2008JB005864

Kita S, Hasegawa A, Nakajima J, Okada T, Matsuzawa T, Katsumata K (2012) High-resolution seismic velocity structure beneath the Hokkaido corner, northern Japan: Arc-arc collision and origins of the 1970 M 6.7 Hidaka and 1982 M 7.1 Urakawa-oki earthquakes. J Geophys Res 117:B12301. https://doi.org/10.1029/2012jb009356

Kita S, Nakajima J, Hasegawa A, Okada T, Katsumata K, Asano Y, Kimura T (2014) Detailed seismic attenuation structure beneath Hokkaido, northeastern Japan: arc-arc collision process, arc magmatism, and seismotectonics. J Geophys Res Solid Earth 119:6486-6511. https://doi.org/10.1002/2014J B011099

Kohketsu K (1985) The extended reflectivity method for synthetic near-field seismograms. J Phys Earth 33:121-131. https://doi.org/10.4294/jpe19 52.33.121

Koketsu K, Miyake H, Fujiwara H, Hashimoto T (2008) Progress towards a Japan integrated velocity structure model and long-period ground motion hazard map. In: Proceedings of the 14th world conference on earthquake engineering, Beijing, China, 12-17 October

Koketsu K, Miyake H, Suzuki H (2012) Japan integrated velocity structure model version 1. In: Proceedings of the 15th world conference on earthquake engineering, Lisbon, Portugal, 24-28 September

Ludwig WJ, Nafe JE, Drake CL (1970) Seismic refraction. In: Maxwell AE (ed) The sea, vol 4. Wiley-Interscience, New York, pp 53-84

Matsubara M, Sato H, Ishiyama T, Van Horne AD (2017) Configuration of the Moho discontinuity beneath the Japanese Islands derived from threedimensional seismic tomography. Tectonophysics 710-711:97-107. https ://doi.org/10.1016/j.tecto.2016.11.025

Nakagawa H, Toyofuku T, Kotani K, Miyahara B, Iwashita C, Kawamoto S, Hatanaka Y, Munekane H, Ishimoto M, Yutsudo T, Ishikura N, Sugawara Y (2009) Development and validation of GEONET new analysis strategy (version 4). Geogr Surv Inst 118:1-8 (in Japanese)

Tichelaar BW, Ruff LJ (1989) How good are our best models? Jackknifing, bootstrapping, and earthquake depth. EOS Trans AGU 70:593-606. https :/doi.org/10.1029/89EO00156

Ueno H, Hatakeyama S, Aketagawa T, Funasaki J, Hamada N (2002) Improvement of hypocenter determination procedures in the Japan Meteorological Agency. Q J Seismol 65:123-134 (in Japanese with English abstract)

Wald DJ, Graves RW (2001) Resolution analysis of finite fault source inversion using one- and three-dimensional Green's functions: 2. Combining seismic and geodetic data. J Geophys Res 106:8767-8788. https://doi. org/10.1029/2000JB900435

Waldhauser F, Ellsworth WL (2000) A double-difference earthquake location algorithm: method and application to the Northern Hayward Fault, California. Bull Seismol Soc Am 90:1353-1368. https://doi.org/10.1785/01200 00006 
Wessel P, Smith WHF, Scharroo R, Luis J, Wobbe F (2013) Generic mapping tools: improved version released. EOS Trans AGU 94:409. https://doi. org/10.1002/2013EO450001

Yoshida S, Koketsu K, Shibazaki B, Sagiya T, Kato T, Yoshida Y (1996) Joint inversion of near- and far-field waveforms and geodetic data for the rupture process of the 1995 Kobe earthquake. J Phys Earth 44:437-454. https:// doi.org/10.4294/jpe1952.44.437

Zhu L, Rivera LA (2002) A note on the dynamic and static displacements from a point source in multilayered media. Geophys I Int 148:619-627. https:// doi.org/10.1046/j.1365-246x.2002.01610.x

\section{Publisher's Note}

Springer Nature remains neutral with regard to jurisdictional claims in published maps and institutional affiliations.

\section{Submit your manuscript to a SpringerOpen ${ }^{\circ}$ journal and benefit from:}

- Convenient online submission

- Rigorous peer review

- Open access: articles freely available online

- High visibility within the field

- Retaining the copyright to your article

Submit your next manuscript at $\boldsymbol{\nabla}$ springeropen.com 